\title{
Major health issues of dyer's working in the textile dyeing industry
}

Received: 16.03.2017; Revised: 01.04.2017; Accepted: 18.04.2017

See end of the paper for authors' affiliations

\section{NAZNEEN JABEEN}

Department of Home Science,

Chhatrapati Shivaji Mahavidhaliya,

Bahadurgarh, HAPUR (U.P.) INDIA
-ABSTRACT : Dyer's is the basic need for textile industry; during work they feel unhealthy due to effect of surrounding environment and activity of the process. In dyeing different kinds of dyeing products are used, which are hazardous in nature and every dye have different impact on dyer's health when exposed to the environment. The natural dye is basically originated from natural sources and a synthetic dye is manufactured by using different kinds of chemical reaction which is hazardous in nature and effect on dyer's health working in textile dyeing industry. So the need of the study was to know the effects of dyes on dyer's health when they have prolong exposes in dyeing process, it is also important to find out the effect of the same on generations health.

KEY WORDS: Dyeing process, Dyer's health, Hazards, Industry

- HOW TO CITE THIS PAPER : Jabeen, Nazneen and Jabeen, Arushi (2017). Major health issues of dyer's working in the textile dyeing industry. Asian J. Home Sci., 12 (1) : 99-103, DOI: 10.15740/HAS/ AJHS/12.1/99-103. 